\title{
Evaluation Capacity Building and Improvement of Monitoring and Evaluation practice among Non- Governmental Organizations in Central Eastern Counties of Kenya
}

\author{
Kithinji Cavens (PhD) \\ Lecturer Department of Community Development Pan Africa Christian \\ University; Nairobi Kenya
}

Doi:10.19044/esj.2019.v15n8p177～URL:http://dx.doi.org/10.19044/esj.2019.v15n8p177

\begin{abstract}
Monitoring and evaluation (M\&E) in projects management is an expensive but critical process that needs careful implementation because of its role in providing information necessary for decision making, planning, and policy formulation. This importance has occasioned the need to look into the quality of M\&E process and a lot of effort has been put into building capacity of $M \& E$ stakeholders in projects and programs. The goal of this study was to establish evaluation capacity building (ECB) efforts and the influence of the same on general M\&E practice among non-governmental organization in central eastern counties of Kenya. The study was guided by pragmatism paradigm to conduct a descriptive survey. Stratified random sampling was used to obtain the sample studied. A structured questionnaire with Likert-type questions, anchored on a five-point scale was used to collect primary data which was triangulated using data from interviews. The findings were that organisations in the region are doing a number of unstructured activities to build evaluation capacity which are done in varying degrees, these activities had influence on M\&E practice. The study recommends organizations to invest in ECB activities especially those that build capacity in M\&E professional development and building M\&E support structures because these were perceived to contribute more to improved M\&E practice. However they need to be systematized and balanced in addressing the M\&E capacity need. Organizations needs to put more resources into. There is also a need to establish and test an ECB model that would be used in a simple in the region.
\end{abstract}

Keywords: Professional-development, resource-allocation, M\&E-support structure, evaluational-environment, M\&E practice. 


\section{Introduction}

There are many reasons found in literature that show the importance of Monitoring and evaluation (M\&E) of project and programs implementation. Monitoring and evaluation provides evidence used in decision making during implementation of projects as necessitated by the various dynamics (Hanh, Hill, Kay, \& Quy, 2009). Besides, project implementation teams always need general feedback on input status and utilization, how well activities are being accomplished and the resulting output. Thus information from M\&E is used in reviewing an on-going project design and also essential in planning for any new related project (Mierlo, Arkesteijn, \& Leeuwis, 2010).

As accountability calls increases, meaningful transparency is now expected of the projects organizations, governments and agencies assisting them. Inclusive $M \& E$ is increasingly being appreciated as a tool to enhance this transparency and to strengthen partnership with various project stakeholders aimed at enhancing ownership (Seasons, 2003; Tilbury, 2007; Scheirer, 2012). M\&E is thus seen as a means through which both internal and external stakeholders interact to get insights on a work well done or otherwise, resources well spent or otherwise and impactful benefits delivered or not.

Monitoring and Evaluation as a system should be designed as tool to enhance learning from project implementation process. Koppel (1986) opined that the call for more efficiency in project activities with clear indicators of development impact and evidence of the same necessitate that project organizations have systems in place that support learning from experience. The views that $\mathrm{M} \& \mathrm{E}$ is also a learning tool beside its contribution to project decision-making and providing evidence of project status and progress has been supported by scholars such as, Tilbury, 2007; Suárez-Herrera, Springett, \& Kagan, 2009; Scheirer, 2012. Because of this, monitoring and evaluation is recognized as an indispensable tool of project management.

In 1998 at a conference in Abidjan, senior officials from 12 African countries together with 21 international agencies for development assistance acknowledged that developing Africa's capacity for M\&E was essential for improving project implementation and general governance. The participant in this conference saw the need for more training in evaluation design, methodology, and practice (OED \& AfrDB, 1998). In a buildup conference in Johannesburg in 2000, African Evaluation Association (AfrEA) acknowledged that developing capacity for $M \& E$ requires building both supply (the skills, tools, technologies, and project framework for evaluation) and demand (awareness of the need for $M \& E$ and understanding of its purpose and uses) for M\&E.

Nine years later in a paper presented by Operations Evaluation Department (OPEV) of African Development Bank (AfDB) in Casablanca Morocco, the same need was noted and a number of efforts aimed at bridging 
the gap were pointed out. They agreed that there was increased effort in emphasizing project effectiveness and that building monitoring and evaluation capacity was necessary for improved measurement of Projects (AfDB, 2009). However, the necessary M\&E capacity building efforts were noted to be relatively limited in these counties. Thus it was agreed that African institutions must do more to strengthen their capacity to monitor and evaluate.

\section{The Concept of Evaluation Capacity Building (ECB)}

The term 'capacity' has been defined in varying dimensions but in this study, it is viewed as 'the ability of people, organizations and society as a whole to manage their affairs successfully' (OECD, 2006). It is a collective term denoting empowerment and general potential to achieve effectively a desired purpose determined beforehand (Baser \& Morgan, 2008; Brinkerhoff $\&$ Morgan, 2010). Thus evaluation capacity can be said to be the ability of an M\&E system to effectively achieve monitoring and evolutional objectives of an organization.

The capacity of an individual, an organization or a society varies from time to time due to both internal and external influences; what is useful today may be out-dated tomorrow (Simister \& Smith, 2010). This variation may bring about deficiencies in the ability in question. Therefore capacity building is seen as a more deliberate process in which people, organizations or society as a whole create, strengthen or maintain this ability over time.

One of the earliest definition of Evaluation Capacity Building by Schaumburg-Muller (1996) puts it as activities which provide support for systems of evaluation, audit, feedback, and learning from policies, programs, or projects performed at various levels. This definition is broadened by the use of the word "activities" since it doesn't point out the specific activities of ECB. He viewed these activities as being separate from $M \& E$ system itself but having a supportive role to ensure sustainability of M\&E system. Hueftle Stockdill, Baizerman and Compton (2002) says that ECB is the intentional work to continuously create and sustain overall organizational processes that lead to quality evaluation and its routine use.

The intent of the organization to boost these M\&E abilities is thus evident from these definitions. Preskill (2008) gave a detailed description of ECB as involving the design and implementation of teaching and learning strategies to help individuals, groups, and organizations, learn about what constitutes effective, useful, and professional evaluation practice. He points out that ECB aims at sustainable evaluation practice-where members continuously ask questions that matter, collect, analyze, and interpret data, and use evaluation findings for decision-making and action.

Sustainable evaluation practice requires the development of systems, processes, policies, and plans that help embed evaluation work into the way 
the organization accomplishes its mission and strategic goals. For evaluation practice to be sustained, participants must be provided with leadership support, incentives, resources, and opportunities to transfer their learning about evaluation to their everyday work (Patton, 2001). When all these are to be packaged well in the ECB concept, its implementation is assumed to improve M\&E activities.

The main goal of ECB was defined by King et al. (2005) as strengthening and sustaining an organization's capacity to; design, implement, and manage effective evaluation projects; access, build, and use evaluative knowledge and skills; cultivate a spirit of continuous organizational learning, improvement and accountability; create awareness and support for program evaluation and self-evaluation as a performance improvement strategy.

According to Boyle et al., (1999), capacity involves three interdependent levels: individual, organizational and the enabling environment that together defines demand, supply and use of evaluation. Therefore we may say that capacity to do evaluation may include the ability to set up evaluation agenda, determining what is to be evaluated and determining which methodology to use in evaluation. Building capacity therefore means developing these abilities at an individual and group level, through inter-active and dialogue activities that are useful for creating knowledge and skills, thereby empowering people for active evaluation. Capacity to do evaluations covers the complete evaluation process, from the demand for evaluation, initiation and carrying out of evaluations, to learning from and disseminating the results (Boyle, 2005). Boyle farther suggests that, capacity includes the evaluation system (policy, legal and institutional arrangements) as well as the wider accountability environment.

M\&E professional development has been occasioned by an exponential demand for high quality evaluations which has brought about a need for professionalism in conducting evaluations as acknowledged by Quesnel and Québec (2010). According to Taylor-Powell and Boyd (2008), this professionalization is seen in activities aimed at building knowledge, beliefs, and skills of individuals in evaluation. This has been the motivation behind trainings at all levels in M\&E cycle. Since evaluation competence could be determined by factors such as, skills, knowledge, and attitudes of individuals towards $\mathrm{M} \& \mathrm{E}$, training of individuals in these factors is key. ECB offers skills and techniques that one must learn in order to conduct evaluation (Huffman, Thomas, \& Lawrenz, 2008). Khan (1998) argued that M\&E function should be looked upon as the collective responsibility in the organization. This means that every person in the organization should have the ability to carry out M\&E. Douglah, Boyd, and Gundermann (2003) suggested a number of activities that are used by development organizations around the word to improve the performance of M\&E. They include among others, team- 
building; coaching; mentoring; exchange visits; technical assistance; short and long-term training. The concern of this study is to determine if these activities results into skill acquisition and professionalism.

Another aspect of ECB is building M\&E support structure. This includes logistical support such as computers, software, networks and transportation which are necessary to enable M\&E practitioners perform efficient M\&E data-gathering, data-entry and analysis (Douglah et at. 2003; King \& Volkov, 2005). When these and other support systems are missing, no amount of professional training and planning would make much difference in M\&E performance. Khan (1998) also suggested that ECB expertise, technology and time are some important support systems within an organization that would influence $M \& E$ practice. Using an $M \& E$ catalyst (an individual in a leadership position who facilitates significant change in other staff members' evaluation knowledge and skills) as an agent of change in $\mathrm{M} \& \mathrm{E}$ is a support mechanism that could be put in place as a support system (García-Iriarte, Suarez-Balcazar, Taylor-Ritzler, \& Luna, 2011).

Related to M\&E support system is allocation of resources to M\&E activities to facilitate human capital, computer hardware and software, vehicles and other needed assets in support of M\&E activities. Based on experience and specifics of each $M \& E$ system, it is possible to determine necessary resources in regards to each $M \& E$ step. The most effective $M \& E$ systems are the ones that match the system's purpose and design with the project's ability to implement it in terms of its capacity (Kithinji, Gakuu, \& Kidombo, 2017). These may be categorized into three; (a) financial capacity to do M\&E; (b) Human capacity to do M\&E (People, skills and knowledge) and (c) Physical capacity to do M\&E (equipment, technology and machines) (UNAIDS, 2008). Taylor-Powell et al. (2008) argues that specific M\&E resources necessary for M\&E also include evaluation and ECB experts, evaluation materials and evaluation champions.

Financial capacity to do $M \& E$ is critical for any work to be undertaken. As argued by Kithinji et al. (2017) the credibility of information gathered from $M \& E$ system that is underfunded would be questionable more so on the quality of that information. A study by CLEAR (Centre for Learning on Evaluation and Results ) of African monitoring and evaluation systems in 2012 revealed that the weight of resources allocated to monitoring systems in Ghana, Kenya and Benin is demonstrated by the extensive reporting mechanisms in place. They noted that lead agencies collate information from other departments and that this action is dependent on capacities of these departments to collect quality information. The study concluded that in all these cases, considerable human and financial resources are put into development of these departments (CLEAR, 2012). 
Creation of an Evaluational environment in an organization is essential to quality M\&E activities. Functioning of any M\&E system depends on creating the right working environment and its acceptability depends on making it part of the organization's culture where M\&E functions are incorporated in the mandate of the organization at the planning stage (Preskill $\&$ Torres, 1999). This would be followed by a Leadership that actively support and convey their support for M\&E process. Khan (1998) suggested some ways of creating this environment. He argued that leaders who understand and express the purpose and value of ECB to others, set evaluation expectations, encourage, nudge, allocate resources, ask critical questions and request studies, encourage inquiry and critique, verbalize their support for evaluation informally and formally, and reward and applaud M\&E efforts helps entrench evaluation in an organization.

Policies, procedures and guidelines that guide evaluation decisions and actions in an organization form an important aspect of Evaluational environment. There should be guidelines on finance allocation, staffing, planning, training and other aspects that would aid the organization in having a direction in M\&E. Carrying out evaluation with no written policy guidelines may results to evaluation becoming equated with end-of-session questionnaires, whose use can limit learning about evaluation options and approaches (Woodhill, 2005)

\section{Monitoring and Evaluation practice}

Combining two definitions from Tilbury (2007) and TACHE (2011), this paper will adopt a working definition of a project M\&E system as a set of plans in a project put in place for the purpose of gathering and analyzing data, reporting processes, necessary supporting conditions and capacities required for $M \& E$ process in order to make a valuable contribution to project decisionmaking and learning. The aspect of supporting conditions and required capacities account for the need of Evaluation Capacity Building (ECB) to enable M\&E to strengthen project design and implementation.

$M \& E$ activities have diverse dimensions in terms of what should be included in it. The practice has so many elements that are technical and complex. In 2009 for example, MERG (Monitoring and Evaluation Reference Group) working with members of the M\&E Capacity-building Technical Working Group (TWG) developed a 12 Components Monitoring \& Evaluation System Assessment tool for UNAIDS and was tested with great success in Guatemala, Moldova, and Zanzibar (UNAIDS, 2009).

The 12 components were not intended to be implemented sequentially; however, they all should be present and working to an acceptable standard in order for M\&E systems to function effectively. It was acknowledged that resource availability may constrain this holistic implementation and suggest 
that organizations should focus on a few fundamental components at the onset and bring in others as funds are available. There are what is considered acceptable standards in $M \& E$ and the complexity of its functions of which project staff are required to understand. This provides the rationale for evaluation capacity building in M\&E. The most fundamental M\&E variables considered essential in $\mathrm{M} \& \mathrm{E}$ practice include but not limited to; setting the purpose of $M \& E$ plan, M\&E plan development, indicator system development, methodologies, data collection and analysis and M\&E plan review.

The Purpose of M\&E plan is tied to its contribution to organizational learning, improving planning, implementation and effectiveness of projects/programs. According to Molas-Gallart (2012) there are three main categories of M\&E purposes; Distributive - using results to inform or determine the distribution of resources across the potential actors and beneficiaries of a specific project, policy or program, Improvement - focusing on deriving lessons from the past experience and adapting activities that evaluation studies concludes as better practice and Controlling - scrutinizing how organizations and individuals use resources to carry out activities to achieve project objectives. All three categories of purposes are critical to project success. As acknowledged by Simister and Smith (2010), achievement of these would require elaborate planning by well skilled personnel. These skills are not natural, thus the need for Evaluation Capacity Building to be able to define objectives that make an M\&E system relevant to the project.

A M\&E plan as a document describes a system which links strategic information obtained from various data collection systems to decisions that improves project/programs (Tilbury, 2007). It is a fundamental document that ensures accountability and measure of success of a project. Its primary goal is to act as a guide to $M \& E$ implementation. An $M \& E$ plan is a living document and thus adjustable to the needs of a program/project. A survey done by Holvoet and Renard (2007) revealed that there is a very fragmented approach towards M\&E planning, and that the focus is overwhelmingly on technical and methodological issues, to the detriment of the overall policy and institutional/organizational set-up. This approach misses a number of vital elements such as, what information is needed and by whom, how often should the information be collected, how to collect it, who to collect it and the implications on the project budget. This makes $M \& E$ technical and may not be effectively done if the stakeholders do not have the right skills to link all these elements.

Indicator system development involves defining all the critical quantitative metric that provides information to monitor performance, measure achievement and determine accountability (UNAIDS, 2010). An indicator is thus a unit of information that document change measured over 
time. It provides evidence of how much has been or has not been achieved. These can be both quantitative measures and qualitative observations that enable a large amount of data to be reduced down to its simplest form (Tilbury, 2009). A good indicator should be clear and concise focusing on a single issue that provides relevant information on a situation - particularly information that provides the strategic insight required for effective planning and sound decision-making.

An indicator is largely influenced by a number of factors but there are three most important among them because of their impact on the credibility of the data; validity- the extent to which a measurement or test accurately measures what is intended to be measured; reliability- the consistency of the data when collected repeatedly using the same procedures and under the same conditions; and bias- any effect during the collection or interpretation of information that may leads to a systematic error in one direction (UNAIDS, 2010). As pointed out by Izurieta et al., (2011), participatory approach in indicator development in which partners agree equally on the identification of criteria and indicators to measure agreed outcomes has the potential of improving on the three conditions above besides bringing equitable participation, decision making and working relationships, which in turn will lead to improved management effectiveness and community outcomes. Having a wide range of stakeholders equipped for this technical exercise is seen as the work of ECB.

Monitoring and evaluation methodologies include both qualitative and quantitative research methods used in Monitoring and Evaluation studies. Because of this, any effort to classify M\&E methodologies has its shortcomings (Mertens, 1999; Weiss, 1998). In practice the logical approach would be negotiating what needs to be assessed and measured, and then finding appropriate methods from the large pool of both qualitative and quantitative methods.

Selection of any one method depends largely on the type of information needed and the skills of those involved. In selecting which methods are relevant for stakeholders in M\&E activities Guijt (1999) suggested use of questions such as; "which task does the method need to accomplish; what unit of analysis does the method have to cope with and what context and medium would be most appropriate?" Having a wrong method makes the whole $M \& E$ process irrelevant since the information gathered may not be useful. All the stakeholders in M\&E thus need to have capacity to determine the appropriate method to use when, how and where. An effective evaluation is not measured by its complexity but by appropriate and correct use of data collection methods, accurate analysis of the data, a solid design based on well-developed evaluation questions and available resources, and the 
use of data to guide decisions (CDC, 2010). The underlying influence of methodologies on the data collection and treatment cannot be over stated.

Linked directly to the methods is development of a system to collect data; the how of a chosen method. How one prepares for data collection influences the quality of the data collected. The following need to be addressed; ethical concerns, preparation of written guidelines for how data collection is to be done, pre-test data collection indicators, instruments and procedures, and training all staff that would collect the data (The Urban Institute, 2004).

In order to meet the needs of M\&E at each level (inputs, outputs, outcomes and impact), the M\&E system needs to draw on information coming from a variety of sources (Keitan , Okidegbe \& Marchant, 2009). A good M\&E system includes a number of design features that ensure the smooth functioning of the system and the validity of $M \& E$ information gathered for utilization. This point to the fact that overall, data collection system is technical in process and the use of information technology and building capacity for those involved is necessary to equip them for the task of evaluation (OECD, 2006).

As an $M \& E$ practice, adjustments to $M \& E$ plan is done after reviews of the plans are done. It is designed to help the project team to quickly review the realism of the M\&E plan and make adjustments if/where necessary as the process continues. This is important in that it checks any unrealistic elements in reference to resources available, the capacity (both skills and time) of staff to effectively collect, analyze and use the data suggested and so on (DíazPuente, Yagüe, \& Afonso, 2008). The aim is to correct the system and keeping it realistic. This is another area of capacity building that is targeted by ECB activities.

\section{Statement of the problem}

Quality of developmental and social projects dependents largely on the ability of the project implementer to demonstrate the achievement of the stated goals of the project. The aspect of monitoring and evaluating implementation provide evidence necessary for this demonstration thus, the importance of doing it right. In this regard organizations have been carrying out capacity building activities aimed at enhancing M\&E practices. This study seeks to explore the demonstrated influence of evaluational capacity building activities on $\mathrm{M} \& \mathrm{E}$ practice in the organizations under study.

\section{Objective of the study}

The study had two objectives; to establish the manner in which NonGovernmental Organizations (NGOs) in eastern central region of Kenya carry 
out evaluation capacity building activities and the demostrated influence of these activities on monitoring and evaluation practice.

\subsection{Methodology}

This study assumed a mixed mode approach to conduct a descriptive survey of the phenomena based on pragmatism philosophical framework (Mackenzie \& Knipe, 2006). This approach was adopted for its ability to consider multiple viewpoints, perspectives, positions, and standpoints of a phenomenon to enable confirmation or corroboration of the findings of each one of them through triangulation and to provide richer data (Johnson \& Onwuegbuzie, 2004; Onwuegbuzie \& Leech, 2006; Johnson, Onwuegbuzie \& Turner, 2007).

The study sought to describe and understand ECB experience, ideas, beliefs, practices and the values of the practice in monitoring and evaluation. In this respect, it generated qualitative data to have an in-depth understanding of the ECB activities as practiced by individual projects and the stakeholder's perspective of the practice in order to draw important lessons for ECB practice (Cooper, Schindler \& Sun, 2006). The data was collected over a short span of time with an aim of making inferences on the influence of ECB activities on M\&E practice thus making the study a cross-sectional survey (Imai \& Nakachi, 1995; Levin, 2006). In making inferences, the study used quantitative data generated from the questionnaire.

\subsection{Target Population}

This study randomly sampled organizations operating in different counties in the central eastern region of Kenya. These counties included Meru, Tharaka-Nithi and Embu counties. The actual Number of registered non-profit organizations in the counties was had to establish because of multiples agencies that register them. However, there exist organizations that have operated within these counties for a number of years. These have operated under government ministries; others are international NGOs, national NGOs and CBOs. The study targeted organizations that had a life span of three or more years and have significant presence in the region. Among these were 21 project organizations working under government ministries and 102 project organizations both international NGOs and national NGOs. The target respondents were 417 personnel working in these organizations consisting of project managers, M\&E managers/officers, project officers, data officers and Project implementing staff.

\subsection{Sample size}

Respondents were drawn from the 102 organizations which have been in operation for more than three years. The overall sample size for this study 
was determined using a formula by Krejcie and Morgan (1970). $s=$ $\frac{x^{2} N P(1-P)}{d^{2}(N-1)+X^{2} P(1-P)}$. The total number of the targeted employees was 417 , thus the sample size was; $\mathrm{n}=\frac{(3.84)(417)(0.5)(1-0.5)}{(0.0025)(417-1)+(3.84)(0.5)(1-0.5)} ; \mathrm{n}=\frac{400.32}{2} ; \mathrm{n}=$ $200.16 \sim 200$.

With the sample size determined, proportional allocations was adopted to distribute the respondents among employee categories aiming to have a percentage of between 47 and 48 as shown in Table 1 below. Thus $\frac{200}{417} \times 100=47.962=48 \%$

Table 1; sample size

\begin{tabular}{llll}
\hline Category & Total Number & Sample size & Percentage \\
\hline Project managers & 78 & 37 & 47.4 \\
M\&E managers/officers & 80 & 38 & 47.5 \\
Project officers & 101 & 49 & 48.5 \\
Data officers & 27 & 13 & 48.1 \\
Project implementing staff & 131 & 63 & 48.1 \\
\hline Totals & 417 & 200 & 47.92 \\
\hline
\end{tabular}

\subsection{Sampling Technique}

To sample the respondents, stratified random sampling was used to ensures that all parts of the population are represented in the sample in order to increase the efficiency of the study (Kothari, 2009; Kotrlik \& Higgins, 2001). The study used job positions (Project managers, M\&E managers/officers, Project officers, M\&E staff and Project staff) held by the respondents in these organizations as strata. To have proportional representation from each stratum, a sample was drawn independently using the same ratio so as to have similar percentage of each total. Random sampling was used to ensure that each element in each stratum had equal probability to be selected for the study.

\subsection{Research instruments}

This study used two instruments to collect data. The questionnaire was used as the main tool for collecting data because it's an objective means of collecting information about people's knowledge, beliefs, attitudes and behavior concerns (Boynton \& Greenhalgh, 2004). In addition to questionnaire, semi structured interviews were used to collect in-depth information. This allowed flexibility since it presented an opportunity to restructure questions as needed (Kothari, 2009). The interview targeted ten key informants (5 project managers and $5 \mathrm{M} \& \mathrm{E}$ managers) with an aim of getting data that was used to verify and add meaning to the data collected using questionnaires. 


\subsection{Data analysis techniques}

Descriptive analysis was done to study distributions of variables as they presented themselves. Correlations coefficient was used to measure relationships. Decision rule followed Cohen (1988) suggested guidelines as used by Shirley, Stanley and Daniel (2005). A R-value of between .10 to .29 means small or weak correlation; R-value of between .30 to .4.9 means medium or moderate correlation and R-value of between .50 to 1.0 means large or strong correlation. These guidelines applied whether or not there was a negative sign out in front of the $r$ value. The negative sign refers only to the direction of the relationship, not its strength.

\section{The findings}

\subsection{Descriptive analysis of $M \& E$ practice}

Evaluation capacity building activities are designed to generally improve $\mathrm{M} \& \mathrm{E}$ practice in organizations. The assumption made in this study was that as organizations undertake more ECB activities, M\&E practice also improves. $M \& E$ practices include a number of $M \& E$ actions carried out in project organizations. The practices explored in this study and their rates of implementation in the region are summarized in Table 2.

\begin{tabular}{llll}
\hline \multicolumn{4}{l}{ Table 2; Descriptive statistics of M\&E Practice } \\
\hline Description & $\mathbf{n}$ & Mean & SD \\
Indicator system development & 172 & 2.8398 & .76141 \\
Development of data collection tools & 172 & 2.6484 & .63722 \\
M\&E plan development & 172 & 2.6264 & .60656 \\
M\&E data dissemination & 172 & 2.6044 & .74149 \\
Formulation of M\&E Purpose & 172 & 2.5824 & .75897 \\
Adjustment of M\&E plans & 172 & 2.5220 & .65398 \\
\hline Composite mean & $\mathbf{1 7 2}$ & $\mathbf{2 . 6 5 7 1}$ & $\mathbf{. 4 2 1 8 2}$ \\
\hline
\end{tabular}

The fact that all the respondents responded to this is an indicator that all the organization sampled carried out monitoring and evaluation. However, the varying degree to which respondents viewed these activities as being practiced among the organizations was not as high as it was expected. This could be explained by the fact that most of these practices are done periodically.

The M\&E practice that was perceived to have been taken more was the development of indicator systems with a mean of 2.8398 and SD of 0.7614 , followed by development of data collection tools with a mean of 2.6484 and SD of 0.63722 . This is significant because these activities are core in any evaluation. The quality of data collected depends on having the right indicator and the tool to measure them. The formulation of M\&E purpose had a low mean of 2.5824 and SD of 0.75897 . Being the basis on which evaluations are directed, it indicates a possibility of $M \& E$ processes that may be too general 
thus may not be able to generate data that meets specific purposes. The M\&E activities that was least performed was adjustment of M\&E plan with a mean of 2.522 and SD of 0.65398 . This could be explained by the fact that not all evaluations would lead to adjustments of M\&E plans if the said plans are consistent with what is happening on the ground.

The composite mean of $M \& E$ practices was 2.6571 with a SD of 0.42182 . This is also seen in the concentration of the respondent scores around the scale of 'to a little extent' and that one of 'to a moderate extent.'

The respondents interviewed revealed that M\&E practices involve all the managers since these activities are done at planning level. However they indicated that capacities need to build in these areas more because as one manager pointed out;

"M\&E activities have become a key element in management. The tools and general methodology is dynamic and the circumstance under which the activities are taken also change"

\subsection{Descriptive analysis of ECB activities}

M\&E professional development (as a variable of ECB) was measured using training and/or workshop on $M \& E$, technical assistance in $M \& E$, collaborative evaluation, M\&E mentoring and coaching programs and seeking membership or belonging to $\mathrm{M} \& \mathrm{E}$ communities of practice as its indicators. The results showed that in the organizations studied, activities that promoted professional development were practiced as presented in Table 3 below.

\begin{tabular}{|c|c|c|c|}
\hline Description & $\mathrm{n}$ & Mean & $\begin{array}{l}\text { Std. } \\
\text { Deviation }\end{array}$ \\
\hline Receives technical assistance in $M \& E$ & 172 & 3.1207 & .92638 \\
\hline Training and/or workshop on M\&E & 172 & 2.8678 & .81871 \\
\hline M\&E mentoring and coaching programs & 172 & 2.5838 & 1.25762 \\
\hline $\begin{array}{l}\text { Collaborative M\&E with other people or } \\
\text { organizations }\end{array}$ & 172 & 2.3276 & 1.16878 \\
\hline Memberships to M\&E community of Practice & 172 & 2.1445 & 1.23747 \\
\hline Composite mean & & 2.6088 & .65322 \\
\hline
\end{tabular}

Receiving M\&E technical assistance was the most popular activity in M\&E professional development among organizations in the counties with a mean of 3.121 and SD of 0.92638 . Training and/or attending workshop on M\&E was done to a moderate extent with a mean of 2.8678 and SD of 0.8187 . M\&E mentoring and coaching programs had a Mean of 2.5838 while the least among these activities was seeking memberships to M\&E community of Practice with a mean of 2.144 and a SD of 1.237.

The composite mean for the ECB activities of professional development was 2.6088 and SD of 0.65322. This means that when measured 
to a five point Likert scale, the activity was performed to a moderate extent. The opinion of the respondents was that these activities had not been given much attention as a means of improving M\&E processes. These results are consistent with another study done earlier whose focus was Professional development in $M \& E$ and its influence on $M \& E$ result utilization (Cavens, Kidombo \& Gukuu et al. 2016).

Allocating resources to $M \& E$ activities as a means build capacity for an evaluation is key to the success of M\&E practice. In this respect, the study measured indicators such as, budgetary allocation for M\&E activities, hiring qualified $M \& E$ personnel and contracting $M \& E$ experts by organizations, buying and use of M\&E reference materials in organization, allocation for training in $M \& E$ and Use of organizations assets in M\&E activities. The result of these are shown in Table 4 below.

\begin{tabular}{llll}
\hline Table 4; Descriptive Statistics of Resource Allocation activities & \\
\hline Description & $\mathrm{n}$ & Mean & Std. Deviation \\
Yearly budgetary allocation for M\&E activities & 172 & 3.0460 & .81755 \\
Use of organizations assets in M\&E activities & 172 & 2.8960 & .85633 \\
Hired qualified M\&E personnel in organizations & 172 & 2.6954 & .85631 \\
Buy M\&E reference materials in our organization & 172 & 2.6724 & 1.06529 \\
Allocations for trainings & 172 & 2.6687 & .85246 \\
Contracting M\&E experts & 172 & 2.6231 & .75862 \\
\hline Composite mean & & $\mathbf{2 . 7 6 6 9}$ & $\mathbf{. 5 6 7 4 7}$ \\
\hline
\end{tabular}

Organizations studied allocated resources in varying degrees in the region. Respondents felt that overall budget was just sufficient to carry M\&E activities at a mean of 3.046 and allowing use of organizations assets almost at the same level with a mean of 2.896. There seems to be little allocation being done for $M \& E$ training at a mean of 2.669 and less in availing funds to contract $M \& E$ experts at a mean of 2.6231 .

The composite mean was 2.7669 and a SD of 0.56747 meaning that organizations are allocating resources for $\mathrm{M} \& \mathrm{E}$ processes to a moderate extent. These results also pointed out to the need for organizations to invest more in $\mathrm{M} \& \mathrm{E}$ especially training, contracting experts and buying $\mathrm{M} \& \mathrm{E}$ reference materials because they form the basis on which evaluators draw their arguments and confidence in what they do since they are backed up by other evaluators' works. These results are consistent with another study done earlier whose focus was $M \& E$ resource allocation and its influence on M\&E result utilization (Kithinji, et al. 2017).

The respondents were asked to make responses on the activities that were taken to build M\&E support structure. The activities considered are presented in Table 5 below. 


\begin{tabular}{llll}
\hline Table 5; Descriptive statistics of building M\&E Support structures & & & \\
\hline Description & $\mathrm{n}$ & Mean & SD \\
& & & \\
& & & \\
M\&E experience sharing between departments and projects. & 170 & 3.0278 & 1.06457 \\
Technical support to improve M\&E practice & 172 & 2.9341 & .83172 \\
Establish M\&E feedback system & 170 & 2.8500 & .87469 \\
Development of internal M\&E standards & 171 & 2.8412 & .84523 \\
Delegating necessary authority to M\&E personnel & 172 & 2.8242 & .86162 \\
Establish linkages with evaluation experts & 171 & 2.4365 & .89604 \\
$\begin{array}{l}\text { Affiliation to M\&E professional bodies and attended any } \\
\text { M\&E forums }\end{array}$ & 170 & 1.2778 & .69359 \\
\hline Composite mean & & & \\
\hline
\end{tabular}

The mean scores of these activities indicate that the most common activity taken in these organizations was sharing M\&E experience between departments and projects with a mean of 3.0278, while technical support to improve M\&E activities had a mean of 2.934. Developing standards for internal monitoring and evaluation of $\mathrm{M} \& \mathrm{E}$ work had a mean of 2.8412 and establishing $M \& E$ feedback system was said to help in passing $M \& E$ information forward and backward within an organization with a mean score of 2.850 .

Management of organizations in the counties delegated authority to $M \& E$ personnel to enable them carryout $M \& E$ activities and make decision in M\&E without restrictions. The mean for this activity was 2.8242 while establishing linkages with evaluation experts as an activity to build M\&E support structure, scored a mean of 2.4365. From this, it was established that organizations did not have continuous linkage with evaluation experts with a view of assisting M\&E personnel to keep in touch with what is considered appropriate practice in $\mathrm{M} \& \mathrm{E}$ and solve any problem that arises from $\mathrm{M} \& \mathrm{E}$ processes.

The least activity in this category was seeking affiliation to M\&E professional bodies and/or attending M\&E forums with a mean of 1.2778 meaning that this activity was done by a small number of organizations.

Overall the composite mean for these activities was 2.543 and a SD of 0.56809 . This means that M\&E support structures were built in the counties to a little extent. This is moderately significant thus there is need to improve these activities in the counties more so on, establishing linkages with evaluation experts and affiliation to professional bodies and/or attending M\&E forums.

Another ECB variables studied was establishing an evaluational environment. The study considered this as the attitude and conditions in the 
organization that help to facilitate $M \& E$ activities where $M \& E$ becomes part of the organization culture and $\mathrm{M} \& \mathrm{E}$ functions are incorporated in the mandate of the organization at the planning stage. The presence of $\mathrm{M} \& \mathrm{E}$ policies and procedures, M\&E guiding values, leadership support for M\&E, demand for and supply of M\&E information were considered as indicators of this and were investigated in this study. Table 6 shows these statistics.

\begin{tabular}{llll}
\hline \multicolumn{4}{c}{ Table 6; Descriptive statistics of activities that create evaluational environment } \\
\hline Descriptions & $\mathrm{n}$ & Mean & SD \\
leadership support for $\mathbf{M} \& \mathbf{E}$ & 172 & 4.2692 & .74998 \\
Constant demand for $\mathbf{M} \mathbf{E}$ data & 171 & 4.1602 & .79005 \\
Supply of M\&E information. & 172 & 3.8572 & .88652 \\
Established M\&E guiding values & 172 & 3.1923 & .98685 \\
Established M\&E policies and procedures & 122 & 2.3077 & .63407 \\
\hline Composite mean & & $\mathbf{3 . 5 5 7 3}$ & $\mathbf{. 4 3 7 0 4}$ \\
\hline
\end{tabular}

The respondents viewed leadership support for M\&E as occurring most often with a mean of 4.269 and a SD of 0.74998 . Here leaders of the organizations were seen as champions in $M \& E$ processes and that they used $M \& E$ results in day to day running of the organizations. It is important to note that no respondent who rated leadership support as absent at all nor to a little extent.

Constant demand for M\&E information had a mean of 4.160 and a SD of 0.79005 . The high mean could be explained by the fact that all organizations sampled dealt with projects and in project management, M\&E is part of the common practice. However, it was established that supply of M\&E information was lower than its demand with a mean of 3.8572 and a SD of 0.88562 . This means that there were fewer evaluations done yet the demand was higher and that organizations were in need of more M\&E information than what was available.

Establishment of M\&E guiding values had a mean of 3.1923 with a SD of 0.98685. This indicates that this was done to a moderate extent. Establishment of M\&E policies and procedure was the least done with a mean of 2.3077 meaning that these were present 'to a little extent'. This scenario may mean that policies and procedures are documented in organizations strategic plans and project plans but not advocated for as much in practice.

The composite mean for all the activities that help create evaluational environment in organizations was 3.5573 and a SD of 0.43704 . This means that overall, these activities were done 'to a great extent' when measured in a 5 point likert scale. This was a significant attempt by these organizations to build capacity for their employees in this area. This was explained by the concentration of the respondents score between the high score of 'to a moderate extent' and 'to a very great extent.' 


\subsection{Manner of implementing ECB activites}

In general, the study sought to find out if the ECB activities were implemented using any order or model. Table 7 below shows the results of this.

Table 7; Descriptive statistics of order or model of ECB implementation.

\begin{tabular}{llll}
\hline Descriptions & n & Mean & SD \\
\hline ECB activities implemented on need bases & 172 & 4.4652 & .72754 \\
$\begin{array}{l}\text { ECB activities were designed and inbuilt in the M\&E } \\
\text { system }\end{array}$ & 168 & 1.2645 & .83457 \\
ECB activities implemented following a thought out model. & 172 & 1.1061 & .64234 \\
\hline Composite mean & & $\mathbf{2 . 2 7 8 6}$ & $\mathbf{. 4 3 7 0 4}$ \\
\hline
\end{tabular}

In general, the data above shows that evaluation capacity building was not being conducted following any model or specific order. Most ECB activities were done on a need basis with a mean of 4.4652 and stadard deviation of .72754. However, it was clear that they were done to build M\&E capacity. As one of the M\&E managers said of his institution;

"Most ECB activities are done when funders want to introduce

a new dimesion in the way $M \& E$ is done or when explaining new tools and templates."

The understanding of evaluation capacity building activities as seen in improving M\&E processes was viewed as important as one M\&E manager said,

"Every time we have a new project, we endeavor to prepare our employees in not only the implementation of the project but on $M \& E$ aspects that need to be checked so as to have information on implementation flowing back to the managers and donors. This helps as it answers a lot of questions on the outcome and ownership of the project."

From this analysis, it is clear that organizations would benefit more if evaluation capacity building is done from a structured approach designed to address each organization's need as may be determined through a detailed need analysis.

\subsection{Correlation analysis of the variables}

Having measured these variables on a likert scale, Pearson Product Moment Correlation was used to determine the direction and strengths of these relationships at $95 \%$ level of confidence. To establish if there was any correlation between ECB activities and M\&E activities, the composite means of the two variables were used in a Pearson Product-Moment Correlation.

Based on the responses, the relationships between ECB activities and the selected M\&E practices were investigated. From the results, coefficient 
of determination and the resulting percentage of variances were calculated to determine the level of influence on M\&E practices explained by ECB activities. Table 8 Show the results of this analysis.

Table 8; Coefficients and variance of ECB and M\&E activities

\begin{tabular}{|c|c|c|c|c|}
\hline $\begin{array}{l}\text { Independent } \\
\text { (ECB Activities) }\end{array}$ & Dependent & $\begin{array}{l}\text { Correlation } \\
\text { coefficient }\end{array}$ & $\begin{array}{l}\text { Coefficient of } \\
\text { determination } \\
\left(r^{2}\right)\end{array}$ & $\begin{array}{c}\text { percentage } \\
\text { of variance } \\
\left(\boldsymbol{r}^{2} * \mathbf{1 0 0}\right)\end{array}$ \\
\hline $\begin{array}{c}\text { Professional } \\
\text { Development } \\
\text { Activities. }\end{array}$ & $\begin{array}{l}\text { M\&E } \\
\text { Practice }\end{array}$ & $\begin{array}{l}{[\mathrm{r}=. \mathbf{5 3 4}, \mathrm{n}=172,} \\
\mathrm{p}<.0005]\end{array}$ & 0.28516 & 28.5 \\
\hline $\begin{array}{c}\text { Resource } \\
\text { Allocation } \\
\text { activities }\end{array}$ & $\begin{array}{l}\text { M\&E } \\
\text { Practice }\end{array}$ & $\begin{array}{l}{[\mathrm{r}=. \mathbf{4 3 4}, \mathrm{n}=172,} \\
\mathrm{p}<.0005]\end{array}$ & 0.1884 & 18.8 \\
\hline $\begin{array}{l}\text { M\&E support } \\
\text { structures }\end{array}$ & $\begin{array}{l}\text { M\&E } \\
\text { Practice }\end{array}$ & $\begin{array}{l}{[\mathrm{r}=. \mathbf{5 1 2}, \mathrm{n}=171,} \\
\mathrm{p}<.0005]\end{array}$ & 0.26214 & 26.2 \\
\hline $\begin{array}{l}\text { Creation of } \\
\text { evaluational } \\
\text { environment }\end{array}$ & $\begin{array}{l}\text { M\&E } \\
\text { Practice }\end{array}$ & $\begin{array}{l}{[\mathrm{r}=. \mathbf{4 4 6}, \mathrm{n}=172,} \\
\mathrm{p}<.0005]\end{array}$ & 0.1989 & 19.8 \\
\hline
\end{tabular}

From the above, we could conclude that ECB activities explains in varying percentanges the variance in respondents' scores on improved M\&E practice scale.

There was an averange positive correlation between professional developement activities and $\mathrm{M} \& \mathrm{E}$ practice with $[\mathrm{r}=.534, \mathrm{n}=172$, $\mathrm{p}=.0005<.05]$. The value of $\mathrm{r}^{2}=0.285$ meaning that professional developement activities explains 28.5 percent of the variance in the respondents score on $\mathrm{M} \& \mathrm{E}$ practice scale. This is significant when considered that this is just one variable in ECB frame work.

The relationship between resource allocation for $\mathrm{M} \& \mathrm{E}$ and $\mathrm{M} \& \mathrm{E}$ practice was moderate with $[\mathrm{r}=.434, \mathrm{n}=172, \mathrm{p}<.0005]$. The coefficient of determination $r^{2}=0.1884$ meaning that allocating resources for M\&E helps to explain $18.8 \%$ of the variance in respondents' scores on improved M\&E Practice scale, meaning that there is a significant overlap between the two variables.

There is a an averange positive correlation between M\&E support structures and $M \& E$ practice with $[\mathrm{r}=. \mathbf{5 1 2}, \mathrm{n}=171, \mathrm{p}<.0005]$. The coefficient of determination $r^{2}=0.26214$ meaning that resource allocation help to explain $26.2 \%$ of the variance in respondents' scores on improved M\&E Practice scale. This shows if allocation of resources is done suffeciently, there would be an improvement in $M \& E$ practice.

There was a moderate positive correlation between activities that help create an evaluational environment within organizations and M\&E practice with $[r=.446, n=172, p<.0005]$. The coefficient of determination $r^{2}=0.1989$ which shows that creation of conducive evaluational environment help explain 
$19.9 \%$ of the variance in respondents' scores on improved M\&E Practice scale meaning that there is little overlap between the two variables. Notice that this score is higher than that of allocating resources meaning that among these organization, having M\&E conducted in the right environment has more meaning.

The relationship between overall ECB activities and M\&E practice was also investigated using Pearson Product Moment Correlation. There was a strong positive correlation were $[\mathrm{r}=.895, \mathrm{n}=182, \mathrm{p}=0.0005<.05]$ as seen in Table 9. The coefficient of determination $\mathrm{r}^{2}=0.8010$ meaning the ECB activities help explain $80.1 \%$ of the respondent score on improved M\&E practice. This means that ECB activities are perceived to contribute to better $M \& E$ practice to great extent.

Table 9; Correlations Joint ECB activities and M\&E activities

\begin{tabular}{llll}
\hline & & Joint ECB activities & M\&E Practice \\
\hline Joint ECB activities & Pearson Correlation & 1 & $.315^{* *}$ \\
& Sig. (2-tailed) & & .000 \\
& $\mathrm{~N}$ & 172 & 171 \\
\multirow{3}{*}{ M\&E activities } & Pearson Correlation & $.895^{* *}$ & 1 \\
& Sig. (2-tailed) & .000 & 172 \\
& $\mathrm{~N}$ & 171 & \\
\hline **. Correlation is significant at the 0.01 level (2-tailed).
\end{tabular}

\subsection{Discussions}

The importance of $M \& E$ as expressed by a number of scholars (Tilbury, 2007; Suárez-Herrera, Springett, \& Kagan, 2009; Hanh, Hill, Kay, \& Quy, 2009 Mierlo, Arkesteijn, \& Leeuwis, 2010 Scheirer, 2012) have been validated in this study. All the organizations under study carried out M\&E in all their project.

As an evaluation capacity building strategy, indicators of professional development were present in all the organizations understudy with a mean of 2.61 and variance of $28.5 \%$ thus underscoring its importance. These finding agrees with Preskill (2008) who saw ECB as involving designing and implementation of teaching and learning strategies to help individuals, groups, and organizations, learn about what constitutes effective, useful, and professional evaluation practice. From the student demand for M\&E data was rated at about 4.2 out of a possible 5. This agrees with Quesnel and Québec (2010) who attributed the call for M\&E professional development to an exponential demand for high quality evaluations. According to Taylor-Powell and Boyd (2008), this professionalization is seen in activities aimed at building knowledge, beliefs, and skills of individuals in evaluation which could be said to be the result of indicators scored in this study. 
The findings of the study established that allocating resources to facilitate $M \& E$ practice was important and was done at an average mean of 2.77, with all 172 organizations represented in the study indicating this importance. The finding established that all ECB strategies in this variable accounted for $18.8 \%$ of the respondents score on improved M\&E practice. This validate the findings of Kithinji, Gakuu, and Kidombo (2017) who argued that, the most effective M\&E systems are the ones that match the system's purpose and design with the project's ability to implement it in terms of its capacity. In this regard, they maintained that the credibility of information gathered from $M \& E$ system that is underfunded would be questionable more so on the quality.

Building M\&E Support Structures as an ECB activity was practiced in almost all the organizations under study. Only two indicators were not present in all 172 organizations sampled. Patton (2001) argued that for evaluation practice to be sustained, participants must be provided with leadership support, incentives, resources, and opportunities to transfer their learning about evaluation to their everyday work. This was supported by this study with respondents feeling that this action accounted for at least $26.2 \%$ of their score on improved M\&E practice. Khan (1998) had also suggested that ECB expertise, technology and time are some important support systems within an organization that would positively influence M\&E practice.

The argument that providing a conducive environment in which $\mathrm{M} \& \mathrm{E}$ is conducted would improve $M \& E$ practice was tested in this study. With a mean score of 3.56, it was established that all organizations sampled for this study took this to be very important. This agrees with the opinion of Preskill and Torres, (1999) who argued that the functioning of any M\&E system depends on creating the right working environment and its acceptability depends on making it part of the organization's culture.

$\mathrm{M} \& \mathrm{E}$ policies and procedures as a guiding concept in designing $\mathrm{M} \& \mathrm{E}$ system was seen in 122 organizations yet they were carrying out M\&E activities. This may result to a negative opinion of $M \& E$ practice as argued by Woodhill (2005) who said that carrying out evaluation with no written policy guidelines may results to evaluation becoming equated with end-of-session questionnaires, whose use can limit learning about evaluation options and approaches.

Overall, it was established in the study that ECB activities accounted for $80.1 \%$ of the respondents score on improved M\&E practice. The results correspond with King et al. (2005) arguments in which they saw the main goals of ECB as efforts designed to strengthen and sustain organization's capacity to; design, implement, and manage effective evaluation projects; access, build, and use evaluative knowledge and skills; cultivate a spirit of continuous organizational learning, improvement and accountability; create 
awareness and support for program evaluation and self-evaluation as a performance improvement strategy. These argument were farther strengthened by Huffman, Thomas and Lawrenz (2008) who saw ECB as a model that would offers skills and techniques that one must learn in order to conduct efficient evaluation.

\section{Conclusion}

It has been proved that Evaluation Capacity Building (ECB) activities in Non-governmental Organization in the area under study contribute to improved M\&E practice. Professional development activities were seen to have higher influence at a variance of $28.5 \%$ on M\&E improved practices followed by activities were designed to build $M \& E$ support structures with a variance of $26.2 \%$.

Activities designed to create a conducive evaluational environment within organizations was seen to contribute about $19.9 \%$ improved M\&E Practice while allocating resources for M\&E as a ECB strategy had a variance of $18.8 \%$.

For all ECB variables, 23 indicators were measured on 5 point Likert scale. Of these 10 had a score of between 2.8 and 3.2 meaning that these were present 'to a moderate extent'. Only 3 indicators measured scored between 3.8 and 4.2 meaning that they were done 'to a great extent'.

This show that there was a need to scale up ECB activities among these organizations to get the better benefits especially when it was established that these activities in the manner that they were carried out could have been responsible for about $80.1 \%$ of the respondent score on improved M\&E practice.

\section{Recommendations}

A comparison of the degree of occurrence of ECB activities in the region and their contribution to improved $M \& E$ practice gives insight on the recommendations from this study. From the findings of this study, the need and the importance of building capacity for M\&E has been established. This means that there is need for organizations to put more resources into building capacity in $\mathrm{M} \& \mathrm{E}$ professional development and building M\&E support structures as they were perceived to have more contribution to improved M\&E practice.

Although organizations appeared to have put more resources in activities that created a better evaluational environment, the perceived contribution of this to M\&E practice was not much though significant. This implies that there is a need to balance ECB efforts based on the established need of project organizations in the region. 
The study revealed that these activities were not designed to follow a certain model. There is need for studies to be done to establish a more efficient model to carry out ECB activities. This would held organizations design and plan ECB activities based on both organizational need and a sequence that would yield better results.

\section{References:}

1. AfDB (2009). Impact of the global economic and financial crisis on Africa. Working Paper Sev ries No. 96. Tunis, Tunisia, African Development Bank.

2. Baser, H., \& Morgan, P. (2008). Study on Capacity, Change and Performance. ECDPM discussion paper.

3. Brinkerhoff, D. W., \& Morgan, P. J. (2010). Capacity and capacity development: Coping with complexity. Public Administration and Development: The International Journal of Management Research and Practice, 30(1), 2-10.

4. Boyle, Richard (2005). Evaluation Capacity Development in the Republic of Ireland. Operations Evaluation Department ECD working paper no. 14. Washington, D.C.

5. Boyle, R., \& Lemaire, D. (1999). Building effective evaluation capacity: Lessons from practice (Vol. 8). Transaction Publishers. Retrieved from http://books.google.com/books?hl=en \&lr=\&id=822G7119hhoC\&oi=f $\underline{\text { nd\&pg }}$

6. Cavens, K., Kidombo, H., \& Gakuu, C. (2016). Professional Development in Monitoring And Evaluation and Result Utilization In Meru Region In Kenya. European Scientific Journal, ESJ, 12(23).

7. CLEAR, (2012). African Monitoring and Evaluation Systems; Exploratory Case Studies. Graduate School of Public and Development Management, University of the Witwatersrand, Johannesburg

8. Cohen, J. (1988). Statistical power analysis for the behavioral sciences. Second Edition. Hillsdale, NJ: Lawrence Erlbaum Associates, Publishers.

9. Cooper, D. R., Schindler, P. S., \& Sun, J. (2006). Business research methods. Retrieved from http://sutlib2.sut.ac.th/sut_contents/H139963.pdf

10. Douglah, M., Boyd, H., \& Gundermann, D. (2003). Nurturing the development of an evaluation culture in public educational agencies. In Annual Conference of the American Evaluation Association, Reno NV. 
11. Fowler, A. (1995) Participatory self-assessment of NGO capacity. INTRAC Occasional Papers No. 10.

12. Guijt, I. (1999). Participatory Monitoring \& Evaluation for Natural Resources Management and Research. Socio-economic Methodologies for Natural Resources Research. Natural Research Institute

13. Hanh, T. T. T., Hill, P. S., Kay, B. H., \& Quy, T. M. (2009). Development of a framework for evaluating the sustainability of community-based dengue control projects. The American Journal of Tropical Medicine and Hygiene, 80(2), 312-318.

14. Holvoet,N. \& Renard, R. (2007)Monitoring and Evaluation Reforms Under Changing Aids Modalities; seeking the middle ground in Aid Dependent Low - income Countries; Antwerp: Institute of Development Policy and Management, University of Antwerp.

15. Hueftle Stockdill, S., Baizerman, M., \& Compton, D. W. (2002). Toward a definition of the ECB process: A conversation with the ECB literature. New Directions for Evaluation, 2002(93), 7-26.

16. Huffman, D., Thomas, K., \& Lawrenz, F. (2008). A Collaborative Immersion Approach to Evaluation Capacity Building. American Journal of Evaluation, 29(3), 358-368. doi:10.1177/1098214008318798

17. Imai, K., \& Nakachi, K. (1995). Cross sectional study of effects of drinking green tea on cardiovascular and liver diseases. Bmj, 310(6981), 693-696.

18. Johnson, R. B., \& Onwuegbuzie, A. J. (2004). Mixed methods research: A research paradigm whose time has come. Educational Researcher, 33(7), 14-26.

19. Johnson, R. B., Onwuegbuzie, A. J., \& Turner, L. A. (2007). Toward a definition of mixed methods research. Journal of Mixed Methods Research, 1(2), 112-133.

20. Keitan, Okidegbe, N., \& Murchant, T. (2009) Wye City Group on Statistics on Rural Development \& Agriculture Household Income. Rome. FAO

21. Khan, M. A. (1998). Evaluation Capacity Building An Overview of Current Status, Issues and Options. Evaluation, 4(3), 310-328. doi:10.1177/13563899822208626

22. Kithinji, C., Gakuu, C., \& Kidombo, H. (2017). Resource Allocation, Evaluational Capacity Building M\&E Results Utilization Among Community Based Organizations in Meru County in Kenya. European Scientific Journal, ESJ, 13(16). 
23. King, J. A., \& Volkov, B. (2005). A framework for building evaluation capacity based on the experiences of three organizations. CURA Reporter, 35(3), 10-16.

24. Koppel, B. (1986). Benefit Monitoring and Evaluation Systems in Development Projects: Notes from Asia. Impact Assessment, 5(1), 9 24. doi:10.1080/07349165.1986.9725567

25. Kothari, C. R. (2009). Research methodology: methods and techniques. New Age International. Retrieved from http://books.google.com/books?hl=en\&lr=\&id=8c6gkbKi4C\&oi=fnd\&pg=PR7\&dq=research+methodology, + methods

26. Kotrlik, J. W. K. J. W., \& Higgins, C. C. H. C. C. (2001). Organizational research: Determining appropriate sample size in survey research appropriate sample size in survey research. Information Technology, Learning, and Performance Journal, 19(1), 43.

27. Krejcie, R.V. \& Morgan, D.W. (1970) Determining sample size for research activities. Educational and Psychological Measurements, 30, 607-610.

28. Izurieta, A., Sithole, B., Stacey, N., Hunter-Xenie, H., Campbell, B., Donohoe, P., \& Wilson, L. (2011). Developing indicators for monitoring and evaluating joint management effectiveness in protected areas in the Northern Territory, Australia. Ecology and Society, 16(3).

29. Levin, K. A. (2006). Study design III: Cross-sectional studies. Evidence-Based Dentistry, 7(1), 24-25. doi:10.1038/sj.ebd.6400375

30. Mierlo, B. van, Arkesteijn, M., \& Leeuwis, C. (2010a). Enhancing the Reflexivity of System Innovation Projects With System Analyses. American Journal of Evaluation, 31(2), 143-161. doi:10.1177/1098214010366046

31. Molas-Gallart, J. (2012). Research Governance and the Role of Evaluation: A Comparative Study. American Journal of Evaluation. doi:10.1177/1098214012450938

32. OED and AfrDB. (1998). Evaluation Capacity Development in Africa: Selected Proceedings. Washington, D.C.: OED, World Bank.

33. OECD (2006). The challenge of capacity development - Working towards good practice. DAC guidelines and reference Series, Paris.www.oecd.org/dataoecd/4/36/36326495.pdf

34. Onwuegbuzie, A. J., \& Leech, N. L. (2006). Linking research questions to mixed methods data analysis procedures. The Qualitative Report, 11(3), 474-498.

35. Patton, M. Q. (2001). Qualitative evaluation and research methods (3rd ed.). Thousand Oaks, CA: Sage Publications, Inc 
36. Preskill, H. (2008). Evaluation's Second Act a Spotlight on Learning. American Journal of Evaluation, 29(2), 127-138. doi: $10.1177 / 1098214008316896$

37. Preskill, H., \& Boyle, S. (2008). A Multidisciplinary Model of Evaluation Capacity Building. American Journal of Evaluation, 29(4), 443-459. doi:10.1177/1098214008324182

38. Preskill, H., \& Torres, R. T. (1999). Evaluative inquiry for learning in organizations.

39. Quesnel, J. S., \& Québec, E. (2010). The Professionalization of Evaluation. From Policies to Results, 164.

40. Scheirer, M. A. (2012). Planning Evaluation Through the Program Life Cycle. American Journal of Evaluation, 33(2), 263-294. doi:10.1177/1098214011434609

41. Schaumburg-Muller, H. (1996). Evaluating capacity building: Donor support and experiences. Report for the DAC (Development Assistance Committee) Expert Group on Aid Evaluation, OECD (Organization for Economic Cooperation and Development). Copenhagen, Denmark: DANIDA

42. Seasons, M. (2003). Monitoring and Evaluation in Municipal Planning: Considering the Realities. Journal of the American Planning Association, 69(4), 430-440. doi:10.1080/01944360308976329

43. Simister, N., \& Smith, R. (2010). Monitoring and Evaluating Capacity Building: Is it really that difficult? International NGO training and research centre (INTRAC). Retrieved from http://dspace.cigilibrary.org/jspui/handle/123456789/27574

44. Stockdill, S. H., Baizerman, M., \& Compton, D. W. (2002). Toward a definition of the ECB process: A conversation with the ECB literature (New Directions for Evaluation, no. 93). San Francisco: Jossey-Bass.

45. Suárez-Herrera, J. C., Springett, J., \& Kagan, C. (2009). Critical Connections between Participatory Evaluation, Organizational Learning and Intentional Change in Pluralistic Organizations. Evaluation, 15(3), 321-342. doi:10.1177/1356389009105884

46. TACHE, F. (2011). Developing an Integrated Monitoring and Evaluation Flow for Sustainable Investment Projects. Economia. Seria Management, 14(2), 380-391.

47. Taylor-Powell, E., \& Boyd, H. H. (2008). Evaluation Capacity Building in Complex Organizations. New Directions for Evaluation. Retrieved from http://www.eric.ed.gov/ERICWebPortal/detail?accno=EJ824994

48. The Urban Institute. (2004). Analyzing Outcome Information. Getting the most from Data. The Urban Institute. 
49. Tilbury, D. (2007). Monitoring and Evaluation during the UN Decade of Education for Sustainable Development. Journal of Education for Sustainable Development, l(2), 239-254. doi: $10.1177 / 097340820700100214$

50. Tilbury, D. (2009). Tracking Our Progress A Global Monitoring and Evaluation Framework for the UN DESD. Journal of Education for Sustainable Development, 3(2), 189-193. doi:10.1177/097340820900300215

51. UNAIDS. (2009) 12 components Monitoring and Evaluation System Strengthening Tool. Geneva UNAIDS

52. UNAIDS. (2008) Guidance on Capacity Building for HIV Monitoring and Evaluation. Geneva UNAIDS.

53. UNAIDS. (2010). An Introduction to Indicators. Geneva UNAIDS.

54. Volkov, B., \& King, J. A. (2007). A checklist for building organizational evaluation capacity. The Evaluation Center: Western Michigan University. Accessed March, 28, 2008.

55. Weiss, C. H. (1998). Methods for studying programs and policies. Upper Saddle River: Prentice Hall. Retrieved from http://wikidevel.sugarlabs.org/images/3/3d/Weiss_Analyzing.pdf

56. Woodhill, J. (2005). M\&E as learning: Rethinking the dominant paradigm. Monitoring and Evaluation of Soil Conservation and Watershed Development Projects. Retrieved from http://www.capfida.mg/km/atelier/wageningen/download 